\title{
Prof. Tilman Sauerbruch: patients with HCC may be benefit from statins
}

Submitted Jul 11, 2017. Accepted for publication Aug 01, 2017.

doi: 10.21037/hbsn.2017.08.01

View this article at: http://dx.doi.org/10.21037/hbsn.2017.08.01

Prof. Tilman Sauerbruch (Figure 1) was Director of the Department of General Internal Medicine at the University of Bonn from 1992 till 2012 and temporary head of the Department of Gastroenterology and Endocrinology at the University of Göttingen from 2012 till 2014. He was President of the German Society of Gastroenterology 2002 as well as of the German Association for the Study of the Liver (GASL) 2010 and has served as a member of several editorial boards, such as GUT, European fournal of Gastroenterology and Hepatology, Digestive and Liver Disease, Fournal of Hepatology. He is co-author and author of numerous medical publications. Prof. Sauerbruch's main research interests are in the fields of complications of liver cirrhosis and biliary tract diseases.

It's our honor to do an interview with Prof. Tilman Sauerbruch. We greatly appreciate him for his time and sharing his experiences and perspectives with us.

\section{HBSN: Do you and your team have any research being conducted? Are there any interesting findings?}

Prof. Sauerbruch: I've been interested in the treatment and pathophysiology of portal hypertension for many years. We are looking for new drugs and new treatments for portal hypertension and the possibility to treat portal hypertension with statins. We also look for modulation of signaling pathways within the myofibroblast or the hepatic stellate cells. In addition, we are evaluating the effect of small TIPS (transjugular intrahepatic portosystemic shunt) lumen as compared to large diameter TIPS. Furthermore we evaluate the effect of nonselective $\beta$-blockers on portal hypertension with respect to hemodynamic response and prophylaxis of bleeding from esophageal varices.

HBSN: What's your attitude towards treating liver diseases with statins? Do you think it's promising?

Prof. Sauerbruch: I think it has an effect. But you must

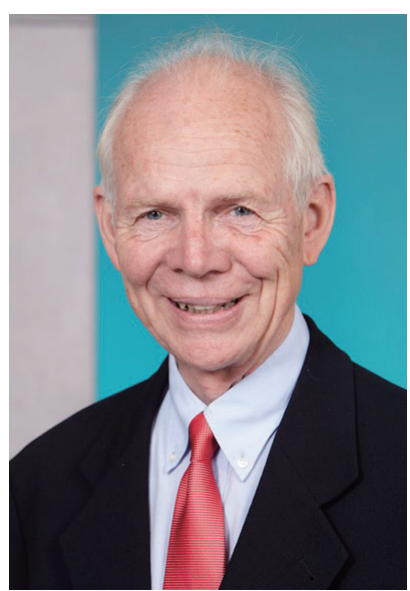

Figure 1 Prof. Tilman Sauerbruch.

select patients with high risks to develop hepatocellular carcinoma, probably those who already have liver cirrhosis induced by chronic viral infection such as hepatitis $\mathrm{B}$ and hepatitis C. There's much evidence by retrospective analyses of large trials that these patients may benefit from statins. But it should be mentioned that in patients with liver cirrhosis, statins may have more adverse effects-like rhabdomyolysis - than in patients without liver disease. So you must check the patients carefully.

The next step, we need and have to perform are prospective control trials; and this is important. It would be very interesting for Chinese young doctors to perform these trials in China, because China has a high rate of chronic $\mathrm{HBV}$ carriers. The effect of statins in chronic alcoholic liver disease and in metabolic liver disease is less clear-cut.

\section{HBSN: Do you have any suggestions on medical education or suggestions for young doctors?}

Prof. Sauerbruch: The first thing is, as a young doctor, you must know what you want and try to be sure whether you want to do research or whether you prefer primarily clinical 
training. It's very important to look into yourself to find out whether you are a good doctor for patients, or whether you should focus on clinical research. It is also possible to combine both. But in this latter situation it is preferable to do one after another in the beginning. In Germany, more than $70-80 \%$ young doctors prefer clinical training and patient work rather than starting research.

Later you often have to decide whether to stay in the academic world or to continue outside academics. If young doctors want to do research, they should try to find a mentor and they should try to find a good group. This is one of the best investments for the future. One can also go abroad for further education but in this case it pays to keep connections with the group. If a young doctor thinks that clinical research does not suit him, but wants to stay in the academic world, she or he can try to engage in medical education.

To sum up, you must know where your strength is and what you want. Thereafter try to find an appropriate senior with a good group. When young doctors are searching for all this, they should be patient and keep in mind that they have time. Young doctors often think they are in hurry. Life is long, although art is longer.

\section{HBSN: As an author, if you would like to submit a paper to a journal, which aspects of a journal will you pay attention to?}

Prof. Sauerbruch: It depends on what sort of authorwhether I am an author doing basic research or clinical research. Most look for the highest-ranking journals in the respective fields, because the impact counts. Furthermore, I have an optimal distribution of my findings if I publish in top journals. But I still believe there is good research hidden in small journals. I have done some very nice and original studies that were published in lower impact journals, but, unfortunately less people read them.

With respect to education, I think it's important to publish in journals of the local and national societies, so that your peers and colleagues learn what you want to tell them.

I think that-at least in Germany-students do not receive sufficient support in publishing articles. Perhaps there should be special journals for students. They could offer and discuss their specific knowledge and problems in a less formal way in such journals.

Last but not least we should not forget the patients. For example, I am at the moment head of an organization with the specific aim to inform patients about gastrointestinal and hepatic diseases in a simple and clear way, to help them to understand their illnesses and to find the suitable doctors.

\section{Acknowledgements}

None.

\section{Footnote}

Conflicts of Interest: The authors have no conflicts of interest to declare.

(Science Editor: Cecilia Jiang, Nicole Li, HBSN, editor@thehbsn.org)
Cite this article as: Jiang C, Li N. Prof. Tilman Sauerbruch: patients with HCC may be benefit from statins. HepatoBiliary Surg Nutr 2017;6(5):365-366. doi: 10.21037/hbsn.2017.08.01 